\title{
Decrease in milk yield associated with exposure to bluetongue virus serotype 8 in cattle herds
}

\author{
S. Nusinovici, ${ }^{*} \dagger{ }^{1}$ C. Souty, ${ }^{*} \dagger \ddagger$ H. Seegers, ${ }^{*} \dagger \ddagger$ F. Beaudeau, ${ }^{*} \dagger \ddagger$ and C. Fourichon ${ }^{*} \dagger \ddagger$ \\ ${ }^{*}$ Oniris, UMR1300 Biologie, Epidémiologie et Analyse de Risque, La Chantrerie, BP 40706, F-44307 Nantes, France \\ †INRA, UMR1300, F-44307 Nantes, France \\ łLUNAM, Université Nantes, Angers, Le Mans, France
}

\section{ABSTRACT}

Decreased milk yield and reduced fertility are the primary consequences of infection by bluetongue virus serotype 8 (BTV-8). These effects must be quantified to fully assess the economic benefit of vaccination. This can be estimated by measuring the effect of BTV-8 exposure on milk yield and fertility for all cows belonging to an infected herd. The objectives of this study were (1) to quantify the mean effect of exposure to BTV-8 on milk yield following natural challenge for cows in herds previously naïve, (2) to determine the duration of reduced milk yield before and after the date disease was first detected in the herd to estimate the cumulative loss of milk yield during this period, and (3) to evaluate the influence of the proportion of infected neighboring herds on the reduction in milk yield following exposure to BTV-8. The effects of exposure to BTV-8 during the French outbreak of 2007 were assessed using mixed linear models, which allow adjustment for factors known to influence milk yield. Exposure to BTV-8 was associated with a sharp decrease in milk yield over a period of 6 mo ( 2 mo before to 4 mo after the reported date of disease detection in the herd). The cumulative loss of milk yield was more than $3 \%$ of annual production. The relatively earlier reduction in milk yield in infected herds detected later in the outbreak period suggests that detection of clinical signs was delayed in these herds. Finally, the greatest decrease in milk yield was observed in herds detected early during the outbreak period and located in areas with the highest disease incidence. This may be due to a greater within-herd incidence or to a greater amount of virus injected by midges to individual cows in these herds.

Key words: bluetongue, milk yield, cow, epidemiology

Received June 4, 2012.

Accepted October 28, 2012.

${ }^{1}$ Corresponding author: simon.nusinovici@oniris-nantes.fr

\section{INTRODUCTION}

The outbreak caused by bluetongue virus serotype 8 (BTV-8) in northern Europe had a major economic impact, mainly due to production losses and control measures (Saegerman et al., 2008; Velthuis et al., 2010). Vaccination, the main control strategy used to contain the spread of the outbreak, has not yet been evaluated economically. Such an assessment requires estimation of the potential benefits of vaccination. These potential benefits correspond to production losses caused by infection in herds, preventable (at least in part) by vaccination. Whereas quantification of losses in infected cows estimates the biological effects of the infection, the quantification of losses among all infected cattle herds estimates the mean effect of infection in these herds.

A decrease in milk yield can be observed both before and after the day clinical signs are first detected in the herd. Time interval between infection and the detection of clinical signs is due to both the incubation period and the time taken for clinical signs to be noticed and reported. The average time of incubation in cattle is estimated at 6 to $8 \mathrm{~d}$, with an interval of between 2 and $18 \mathrm{~d}$ (Thiry et al., 2008). In addition, it has been estimated that it may take up to $2 \mathrm{wk}$ for apparent clinical signs to be reported (Elbers et al., 2008; Saegerman et al., 2010). This could account for reduced milk yield before disease detection in the herd. Furthermore, as the spread of virus within the herd is dependent upon the abundance of vectors (midges) and the exposure of cattle to their bites, all animals in a herd are not infected at the same time. Finally, the effect of infection on milk yield may persist for several days up to several weeks. Reduced milk yield may be due to clinical signs that result in decreased food intake, such as oral and foot lesions. Considering all these factors, determining the duration of reduced milk yield in a herd requires quantification over a broad time period encompassing the date disease was detected in the herd.

Although a decrease in milk yield in cattle herds exposed to BTV-8 has been previously reported (Elbers 
et al., 2009; Saegerman et al., 2010), only one study attempted to quantify the reduction (Santman-Berends et al., 2011). This study compared the milk yield for cows which had seroconverted to BTV-8 with those which had not. They estimated an average yield loss of between 28 and $94 \mathrm{~kg}$ of milk per lactation, representing less than $1 \%$ of total yield during lactation. However, this study may not be representative because of the limited number of cows (91 cows in 15 herds). Furthermore, the authors reported reduced milk yield up to $30 \mathrm{~d}$ before seroconversion was detected.

At the herd level, the mean effect of infection with BTV-8 on milk yield depends on the proportion of infected cows. In France at the end of the 2007 epidemic, it was shown within regions that within-herd disease prevalence increased as between-herd prevalence increased (Durand et al., 2010). The within-herd prevalence was less than 0.10 in regions, with a between-herd prevalence $<0.60$, whereas it increased to between 0.42 and 0.99 in regions with a higher between-herd prevalence of approximately 1.00 (95\% CI: 0.93 to 1.00). Therefore, the mean effect of BTV-8 infection on herd milk yield could increase with the proportion of infected herds in the local geographic area. The proportion of infected cows per herd may also depend on the month of exposure during the outbreak due to the seasonality of vector abundance. Therefore, the average effect of infection on herd milk yield could also vary by month of exposure.

The objectives of this study were (1) to quantify the mean effect of exposure to BTV-8 following natural challenge on milk yield for all cows in herds previously naïve, (2) to determine the duration of reduced milk yield before and after the date disease was first detected in the herd to estimate the cumulative loss of milk yield during this period, and (3) to evaluate the influence of the proportion of infected neighboring herds on the reduction in milk yield following exposure to BTV-8.

\section{MATERIALS AND METHODS}

\section{Study Protocol and Available Data}

Milk yield of cows belonging to exposed herds was compared with that of cows in unexposed herds. Exposed herds from the 2007 French epizootic were selected to quantify the effect of exposure in a population of naïve, unvaccinated cows against BTV-8. In 2006, only 6 exposed herds were reported in France.

Information regarding exposure to BTV-8 was obtained from the official surveillance system. This information was only available at herd level; the status of individual cows was unknown. The exposed herds were reported following either detection of clinical signs by the farmer or veterinarian or in the event of a positive serological test conducted either before the sale or transfer of animals or in sentinel herds (sentinel herds were used for the active surveillance to follow precociously the progression of the epizootic wave). Only exposed herds reported following the detection of clinical signs were included in the analyses, as the date of the serological test does not necessarily identify the date of exposure, given that seroconversion may have occurred long before the test was conducted. A herd was considered exposed if at least 1 animal showing clinical signs tested positive for BTV-8. The exposed herds were selected from the 19 regions with the highest reported prevalence in 2007 (39 regions were reported with at least 1 exposed herd). These selected exposed herds accounted for $92 \%$ of all reported exposed herds in 2007 and will be referred to as case herds.

Milk yield data were obtained from herds registered in the official milk recording scheme. The data included milk yield per test day (TD; over $24 \mathrm{~h}$ ), date of TD and calving dates, and any available data known to influence the performance of milk yield, such as parity, EBV for milk (calculated from previous lactations and the genetic potential of each parent), and breed of cows.

\section{Definition of Exposure to BTV-8 in the Herd According to Spatial and Temporal Distribution of the Disease}

The date that clinical signs of disease were first observed (defined as the date of the clinical suspicion) and the date of diagnostic confirmation were available for each case herd. The proportion of infected cows in a case herd was unknown. It was assumed that the proportion of infected cows in an exposed herd was related to the proportion of newly reported herds in a local geographical area. Therefore, case herds were classified by level of exposure in their local area. The geographical unit was the French district, or canton, with an average of 47 herds per district in 2007. Each district was classified into 1 of 3 categories of exposure according to the value of the monthly peak incidence of exposure. The 3 levels of exposure were high exposure (monthly peak incidence $\geq 0.25$ ), moderate exposure (monthly peak incidence $\geq 0.10$ and $<0.25$ ), and low exposure (monthly peak incidence $<0.10$ ). This classification was done to evaluate the influence of the proportion of infected neighboring herds on the reduction in milk yield following exposure to BTV-8. Monthly incidence was defined as the number of new exposed herds per month in a district divided by the total number of cattle herds in the district. All cattle herds, dairy and beef, were included in the calculation of monthly incidence by district. 


\section{Estimated Dates of Exposure}

The dates of clinical suspicions were used as the estimated exposure dates. The same date of exposure was assigned to all cows from the same case herd. To assign a date of exposure to case herds with no date recorded (6.1\% of all case herds), an imputation procedure based on the distribution of the interval between the suspected and confirmed dates was used. In addition, 181 case herds with an unusual interval between the suspected and confirmed dates (range greater than 30 $\mathrm{d}$ or date of confirmation before suspected date) were excluded. After these exclusions, there were 8,279 case herds located in 534 districts. The dates of exposure ranged from July 31 to December 28, 2007.

\section{Selection of TD and Exposed Lactations Depending on the Time of Exposure in Relation to Lactation}

To monitor changes in an individual cow's milk yield over time, all TD for an exposed lactation were retained. Lactations were considered to be exposed if the date of exposure was between $100 \mathrm{~d}$ before the first and $120 \mathrm{~d}$ after the last TD. This wide range allowed the inclusion of most cows in a case herd, each at a different stage of lactation when disease was suspected. Following this selection process, calving dates of the selected lactations were between April 27, 2006, and March 15, 2008.

\section{Selection of Unexposed Herds and Cows}

Lactations recorded between 2004 and 2006 for cows in case herds were used as the unexposed reference population. This enabled the comparison of cows within the same herd, thereby controlling for farming and climatic conditions (with the exception of a change of farmer during the study period).

Month of calving is known to affect milk yield (Detilleux et al., 1994; Gröhn et al., 1999); therefore, unexposed cows were selected by calving date to ensure a similar time of year for lactations in both the exposed population and the reference population. Calving dates for the reference population were between April 27, 2004, and March 15, 2006.

\section{Selection of Data from TD}

Given the effect of breed on milk yield, only data from Holstein cows were included (Lescourret and Coulon, 1994). Cows with distinctive or implausible data were excluded: parity $>7$, the time interval between 2 TD $>73 \mathrm{~d}$ (to enable the inclusion of consecutive TD despite the delays due primarily to the summer holidays), $<3$ TD per lactation (to enable monitoring of milk yield during lactation), milk yield over $24 \mathrm{~h}$ $>60 \mathrm{~kg} / \mathrm{d}$, age at first calving for primiparous cows between 23 and $37 \mathrm{mo}$, and time interval between TD and calving date $>365 \mathrm{~d}$ (maximum expected from a lactation in France).

\section{Selection of Exposed TD According to the Interval Between TD and the Date of Exposure of the Herd}

The exposure variable, created to account for the time interval between the date of TD and the date of exposure of the herd, enabled examination of the effect of exposure to BTV-8 on milk yield around the time of exposure. Assuming that the detection of the disease can be delayed and that the effect on milk yield can last a long time, a broad time interval around the date of exposure was considered. This interval was extended on both sides to include TD that were probably not exposed. That allowed checking of the comparability of exposed and reference populations without exposure. Consequently, TD were selected from $259 \mathrm{~d}$ before to $265 \mathrm{~d}$ after exposure. This interval was divided into 7-d blocks (which corresponds to 75 categories of exposure) to have sufficient data for each assessment point. Two additional categories of exposure were considered for TD conducted more than $259 \mathrm{~d}$ before exposure and those conducted more than $265 \mathrm{~d}$ after exposure.

\section{Stratification of Analyses According to the Cows' Parity, the Month of the Herd's Exposure, and the Level of Exposure Within the District}

The shape of the lactation curve and the amount of milk produced varies depending on the parity of the animal. In addition, the effect of exposure could vary by parity. Therefore, it was decided to stratify the analyses by parity. Three strata were considered: primiparous (first lactation), parity 2 (second lactation), and parities 3 to 7 (3+ lactation).

The mean effect of exposure to BTV-8 on milk yield in a herd could increase with the proportion of infected herds in the local geographic area and vary by month of exposure. Therefore, a different model was used for either the district (3 strata corresponding to the 3 exposure levels: high, moderate, and low exposure) or the month of exposure (4 strata corresponding to the months from September to December).

\section{Statistical Models}

The statistical unit was the TD. This level was chosen to study the effect of exposure during lactation and to take the factors of temporal variation in milk 
yield into account. The analysis of longitudinal data is more informative than analysis based on cumulative production time per animal (Gröhn et al., 1999). These continuous data also enable the evaluation of the risk period of decreased milk yield due to viral exposure.

The relationship between milk yield and exposure to BTV-8 was estimated using mixed linear models to account for the nonindependence (1) of cows from the same herd and (2) TD from the same lactation (repeated measurements over time). These data characteristics have been taken into account by including (1) a random variable corresponding to herd number and (2) an autocorrelation structure of order 1 between TD. The autocorrelation structure, known as autoregressive, adjusts for the fact that milk yield for a given TD is correlated with the milk yield of the previous TD (Gröhn et al., 1999). The correlation structure of order 1 between the measures of milk yield from a single cow during her lactation requires the estimate of a single correlation parameter $(\Phi)$. The residual at time $t$ is modeled as a function of the residual at time $t-1$ and a residual error:

$$
\varepsilon_{t}=\Phi \times \varepsilon_{t-1}+\eta_{t}
$$

with $\varepsilon_{t}=$ residual from $\mathrm{TD}_{t}, \varepsilon_{t-1}=$ residual from $\mathrm{TD}_{t-1}$, and $\eta_{t}=$ residual error from $\mathrm{TD}_{t}$.

Factors known to affect milk yield must be considered when assessing the effect of BTV-8 (Fourichon et al., 1999; Bareille et al., 2003; Beaudeau et al., 2007). Equation 2 describes the model used for parity 2 cows:

$$
\begin{gathered}
Y_{l m t}=\alpha+E X P_{i}+S L_{j}+M O_{k}+B V_{l} \\
+H E R D_{m}+\left(\Phi \times \varepsilon_{l m(t-1)}+\eta_{l m t}\right),
\end{gathered}
$$

where $Y_{l m t}$ is the milk yield recording at time $t$ of the cow $l$ of the herd $m ; \alpha$ is the intercept, $E X P_{i}$ is the fixed effect of exposure to BTV-8 (78 classes), $S L_{j}$ is the fixed effect of stage of lactation (41 classes corresponding to $5 \mathrm{~d}$ in early lactation, $10 \mathrm{~d}$ in mid lactation and $15 \mathrm{~d}$ in late lactation), $M O_{k}$ is the fixed effect of month of TD (12 classes), $B V_{l}$ is the fixed effect of the estimated breeding value for milk (quantitative, after having checked the linearity with milk yield), $H E R D_{m}$ is the random herd effect, $\Phi$ is the correlation parameter between 2 consecutive TD of the same lactation, $\varepsilon_{\operatorname{lm}(t-1)}$ is the residual associated with the recording $\mathrm{t}-1$, and $\eta_{\text {lmt }}$ is the error term associated with the recording $t$.

For primiparous cows, an additional variable was added to model 2 to adjust for age at calving (quantitative, after having checked the linearity with milk yield). Finally, for parities higher than 3, a parity variable was added (5 classes).

\section{Estimated Milk Yield Cumulated Losses Associated with Exposure to BTV-8}

Cumulative losses in milk yield associated with exposure to BTV-8 were quantified using values estimated by statistical models. These cumulative losses were calculated during the periods of significant milk losses around the date of exposure of the herd and using the exposure level of the district and the month of herd exposure for parity 2 cows.

\section{RESULTS}

\section{Descriptive Statistics}

The mean yield per TD was $26.7 \mathrm{~kg} / \mathrm{d}$ for the whole exposed population (calculated during the exposure period) and $26.5 \mathrm{~kg} / \mathrm{d}$ for the reference population (Table $1)$. The number of herds exposed to the virus in the moderate exposure districts (the most numerous) was almost twice that of districts with high or low exposure. More than $70 \%$ of case herds were reported in September and October. A comparable distribution of parity classes (primiparous, parity 2, and parities 3 and above) existed among selected cows. The high exposure districts were spread over a small area in northeastern France, whereas the moderate and low exposure districts were spread over a larger area including central France (Figure 1a).

\section{Decrease in Milk Yield Associated with Exposure to BTV-8}

Exposure to BTV-8 was associated with a sharp decrease in milk yield around the time of herd exposure. The estimated variations in milk yield per TD are shown in Figure 2 as a function of the time interval between TD and time of case herd exposure for cows in their second lactation in the most exposed districts. Each point corresponds to milk yield changes estimated by the model between highly exposed populations and the reference population for each class of the exposure variable. The negative and positive abscissas correspond to TD made before and after the date of clinical suspicion, respectively. The decrease in milk yield continued long after the date of clinical suspicion in the herd. One hundred and twenty days after exposure, milk yield stabilized, and then decreased again $200 \mathrm{~d}$ after exposure. A decrease in milk yield was observed from $150 \mathrm{~d}$ before exposure of the herd. Two marked decreases in milk yield were noted at 126 and $63 \mathrm{~d}$ before exposure of the herd. The maximum decrease in milk yield per TD was $2.3 \mathrm{~kg}$ and occurred $1 \mathrm{wk}$ after the herd exposure. Due to the low number of TD conducted $260 \mathrm{~d}$ before and 
Table 1. Mean milk yield (MY) per test day (TD) and distribution of the number of herds, cows, and TD according to the stratification factors (in 3,016 Holstein dairy herds; 2004-2008; France)

\begin{tabular}{|c|c|c|c|c|}
\hline Stratification factor & $\begin{array}{l}\text { Number } \\
\text { of herds }\end{array}$ & $\begin{array}{l}\text { Number } \\
\text { of cows }\end{array}$ & $\begin{array}{l}\text { Number } \\
\text { of TD }\end{array}$ & $\begin{array}{l}\text { Average MY } \\
\text { by TD }(\mathrm{kg} / \mathrm{d})\end{array}$ \\
\hline \multicolumn{5}{|c|}{ Level of exposure at district level } \\
\hline High exposure & 890 & 46,405 & 548,649 & 26.0 \\
\hline Moderate exposure & 1,341 & 75,070 & 894,023 & 26.9 \\
\hline Low exposure & 669 & 35,329 & 414,285 & 27.1 \\
\hline Not exposed & 2,974 & 164,854 & $2,044,456$ & 26.5 \\
\hline \multicolumn{5}{|l|}{ Month of exposure } \\
\hline September & 1,050 & 57,339 & 680,733 & 26.5 \\
\hline October & 1,003 & 54,645 & 653,641 & 26.5 \\
\hline November & 538 & 28,183 & 331,265 & 27.0 \\
\hline December & 232 & 12,168 & 141,405 & 26.7 \\
\hline \multicolumn{5}{|l|}{ Parity } \\
\hline Primiparous & 2,997 & 154,358 & $1,427,977$ & 24.4 \\
\hline Parity 2 & 2,988 & 114,103 & $1,039,180$ & 27.3 \\
\hline Parities 3+ & 2,989 & 104,979 & $1,441,240$ & 28.3 \\
\hline
\end{tabular}

${ }^{1}$ The mean milk yield per TD by exposed cows was calculated from all lactation recordings for which the date of clinical suspicion in the herd was between $100 \mathrm{~d}$ before the first and $120 \mathrm{~d}$ after the last TD.

after herd exposure, these recordings were grouped into 2 categories (more than 260 before and more than 260 d after exposure of the herd).

To test the robustness of the results and limit the possible selection bias, a second reference population of cows belonging to herds located in areas that were not exposed in 2007 (Brittany and the southwest of France) was selected (data not shown). The shape of the curve of the estimated values of milk yield was similar.

All adjustment variables were significantly associated with milk yield $\left(P<10^{-4}\right)$, which confirms the interest of having accounting for these variables in the models. Directions of all the relationships correspond to the existing knowledge. Milk yield between January and May was higher than between June and December (Figure 3 ). The progression of milk yield within lactation conformed to biological knowledge (common-shaped lactation curve). The mean milk yield per TD ranged from $35 \mathrm{~kg}$ at the peak of yield (about 1 mo after calving) and $17.4 \mathrm{~kg}$ in late lactation. Milk yield increased with the EBV for milk (regression coefficient $=0.055,95 \%$ $\mathrm{CI}=0.054-0.056)$. In the sample studied, the maximum variation of milk yield due to the EBV differences was $13 \mathrm{~kg}$ per TD. With regard to primiparous cows, milk yield increased with age at calving (regression coefficient $=0.08,95 \% \mathrm{CI}=0.079-0.081)$.

\section{Decrease in Herd Milk Yield Associated with Exposure to BTV-8 According to Month of Exposure}

Figure 4 shows the estimated changes in milk yield according to the time interval between the TD and the exposure time of the herd for each month of exposure. Cows in second lactation in case herds located in moderate-exposure districts were selected for this analysis due to the low numbers of herds exposed in November and December in the high-exposure districts (Figure 1b). The magnitude of the decrease in milk yield was similar for each month of exposure. However, the period of decreased milk yield was earlier, relative to the date of clinical suspicion, in herds detected late in the outbreak period.

\section{Decrease in Milk Yield Associated with Exposure to BTV-8 by Level of Exposure in the District}

Figure 5 shows the estimated changes in milk yield depending on the time interval between the TD and time of herd exposure for second-lactation cows according to the incidence of infected herds at the district level (3 levels of exposure), regardless of month of herd exposure. A greater decrease in milk yield occurred for cows in case herds in high-exposure districts than for those in low-exposure districts. The decrease in milk yield occurred earlier for cows in case herds located in moderate-exposure districts.

\section{Quantification of Cumulative Losses in Milk Yield Associated with Exposure to BTV-8}

The estimated cumulative losses in milk yield associated with exposure to BTV-8 depended on the milk yield values selected for the reference milk yield. Therefore, 3 baseline scenarios were selected, considering the reference milk yield as (1) the milk yield of cows from unexposed herds (Figure 6a), (2) the restabilized milk yield of cows from case herds $130 \mathrm{~d}$ after the date of clinical suspicion (Figure $6 \mathrm{~b}$ ), and (3) milk yield of cows from case herds $100 \mathrm{~d}$ before the date of clinical suspicion (Figure 6c). 


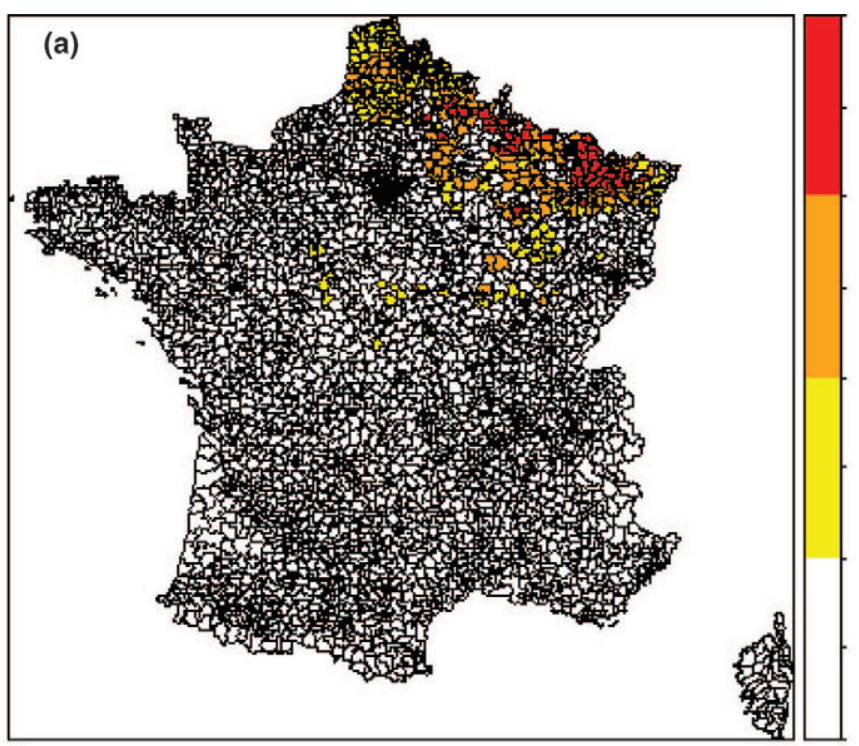

Highly exposed districts

Moderately exposed districts

Slightly exposed districts

(b) Highly exposed

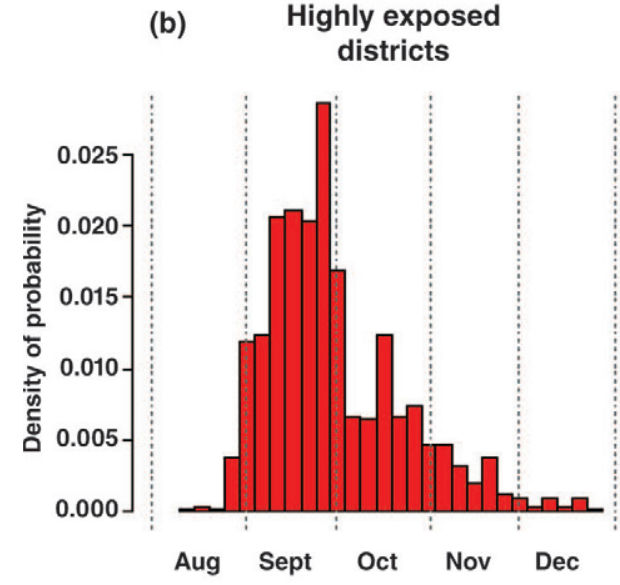

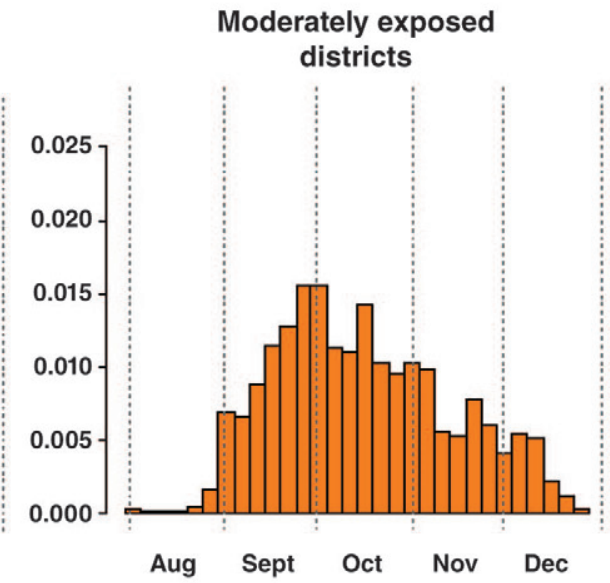

Month on clinical suspicion of the herd

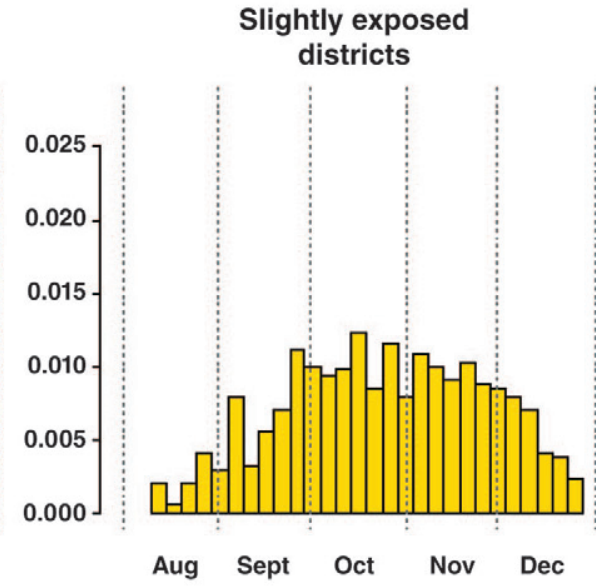

Districts not selected

Aug Sept Oct Nov Dec

Figure 1. (a) Classification of districts by level of exposure to the bluetongue virus serotype 8 (BTV-8) and location of unexposed selected districts in 2007 in France. (b) Distribution of herd dates of clinical suspicion according to the level of exposure to BTV-8 in the district. The exposure level was assigned according to the monthly peak incidence of infected herds. High-exposure districts: districts with a monthly peak incidence $\geq 0.25$; moderate-exposure districts: districts with a monthly peak incidence of $\geq 0.10$ and $<0.25$; low-exposure districts: districts with a monthly peak incidence $<0.10$; selected unexposed districts: districts where no herd infections of BTV-1 or BTV-8 were reported in 2007 and located in Brittany or the southwest of France; districts not selected: districts, either exposed or unexposed, that were not selected in the analyses. Color version available in the online PDF.

Cumulative losses in milk yield between $63 \mathrm{~d}$ before and $118 \mathrm{~d}$ after the date of clinical suspicion in the herd were calculated by adding the intercept of each model to the estimated variations of the effect of the stage of lactation on milk yield and by combining the first 305 d of lactation (Table 2). These losses were calculated by parity for cows in herds located in high-exposure districts. The estimated loss of milk yield for primiparous was lower than estimated loss for older cows. The mean losses estimated for parity 2 animals and animals of parity 3 and above were similar. In the worst-case sce- nario (reference milk yield $=$ milk yield of unexposed cows), animals from the high-exposure districts lost a mean of $3.4 \%$ of their total annual milk yield, regardless of the parity $(2.8 \%$ considering all case herd cows, regardless of the level of exposure of the district). In the best-case scenario (reference milk yield $=$ milk yield of cows exposed $100 \mathrm{~d}$ before exposure), the animals from herds in the high-exposure districts lost a mean of $1.2 \%$ of their total annual milk yield.

Cumulative losses in milk yield associated with exposure to BTV-8 were estimated using the exposure 


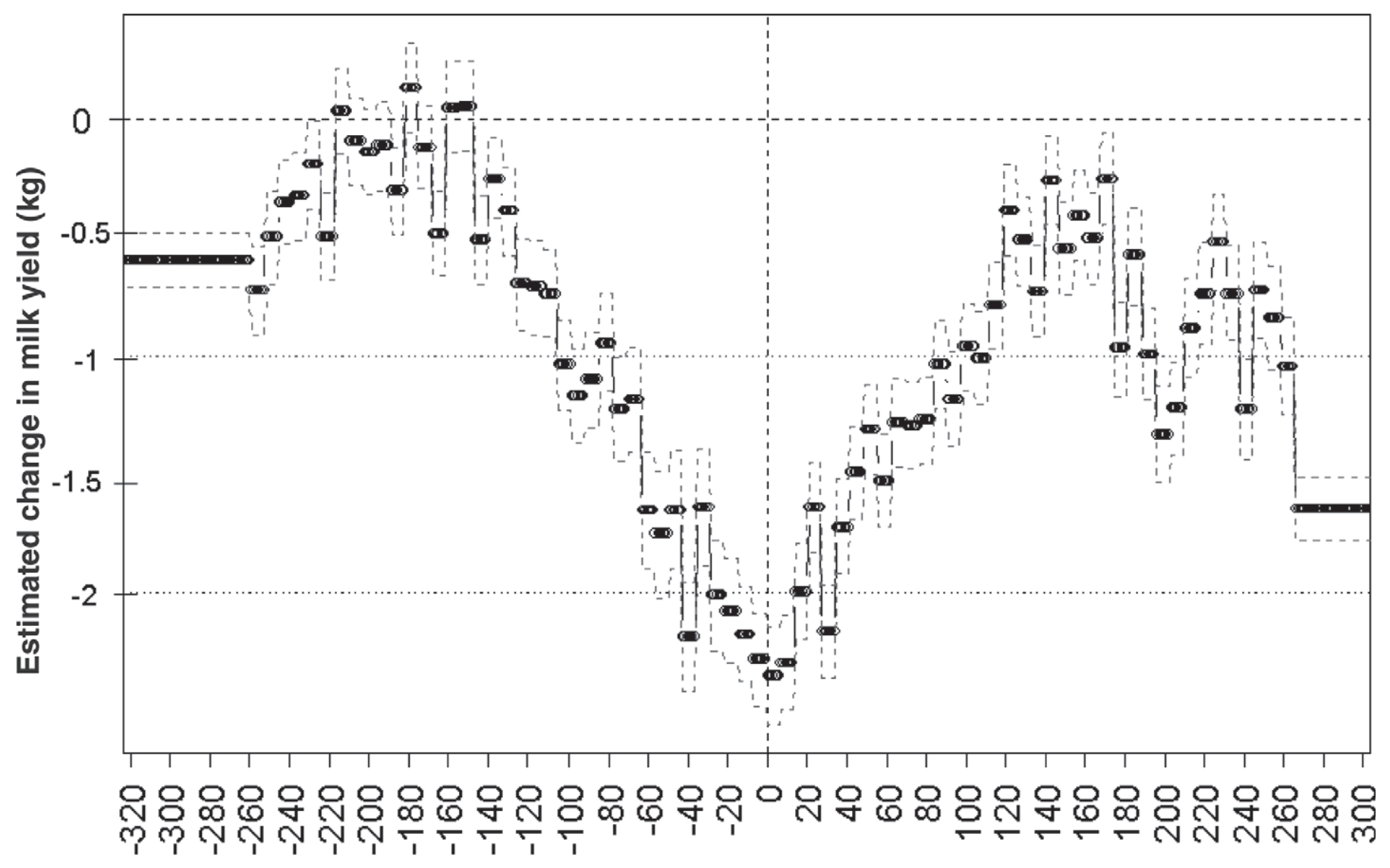

\section{Days before and after date of clinical suspicion}

Figure 2. Estimated changes in milk yield $(\mathrm{kg})$ by milk yield test day and $95 \%$ confidence intervals around the herd date of clinical suspicion for parity 2 cows in herds located in high-exposure districts (exposed population: 15,754 cows in 873 herds; unexposed population: 164,854 cows in 2,974 herds). Each point corresponds to milk yield changes estimated by the model between highly exposed populations and the reference population for each class of the exposure variable.

level of the district and the month of herd exposure for parity 2 cows (Figure 7). For case herds infected in September, losses were calculated over a period of 63 d before to $118 \mathrm{~d}$ after herd exposure. The period of reduced milk yield was earlier relative to the date of clinical suspicion for case herds suspected during the end of the outbreak period (Figure 4). The losses were calculated accounting for the delay in effect according to the month of herd exposure. Thus, the losses were offset by 1 mo in October (period of $93 \mathrm{~d}$ before to 88 $\mathrm{d}$ after the exposure of the herd), 2 mo for November (period of $123 \mathrm{~d}$ before to $58 \mathrm{~d}$ after the exposure of the herd), and 3 mo for December (period of $153 \mathrm{~d}$ before to $28 \mathrm{~d}$ after the exposure of the herd). Overall, estimated losses were lower the later in the outbreak a herd was exposed (249, 238, 211, and $207 \mathrm{~kg}$ for cows belonging to herds exposed in September, October, November, and December, respectively). However, when considering the exposure level of the district, this effect was only apparent for cows belonging to herds in the highexposure districts. Irrespective of herd-exposure month, estimated losses were lower for cows belonging to herds located in the low-exposure districts compared with moderate- or high-exposure districts $(236,237$, and 205 $\mathrm{kg}$ for cows belonging to herds located in the high-, moderate-, and low-exposure districts, respectively). When considering the herd-exposure month, estimated losses decreased according to the level of exposure in the district for herds with a suspected infection date in September and October.

\section{DISCUSSION}

Exposure to BTV-8 in 2007 was associated with a sharp decrease in milk yield in naïve cows. This reduction was detected over a 6 -mo period around the first suspicion of disease in infected herds. The maximum mean reduction in milk yield was $2.3 \mathrm{~kg}$ and corre- 


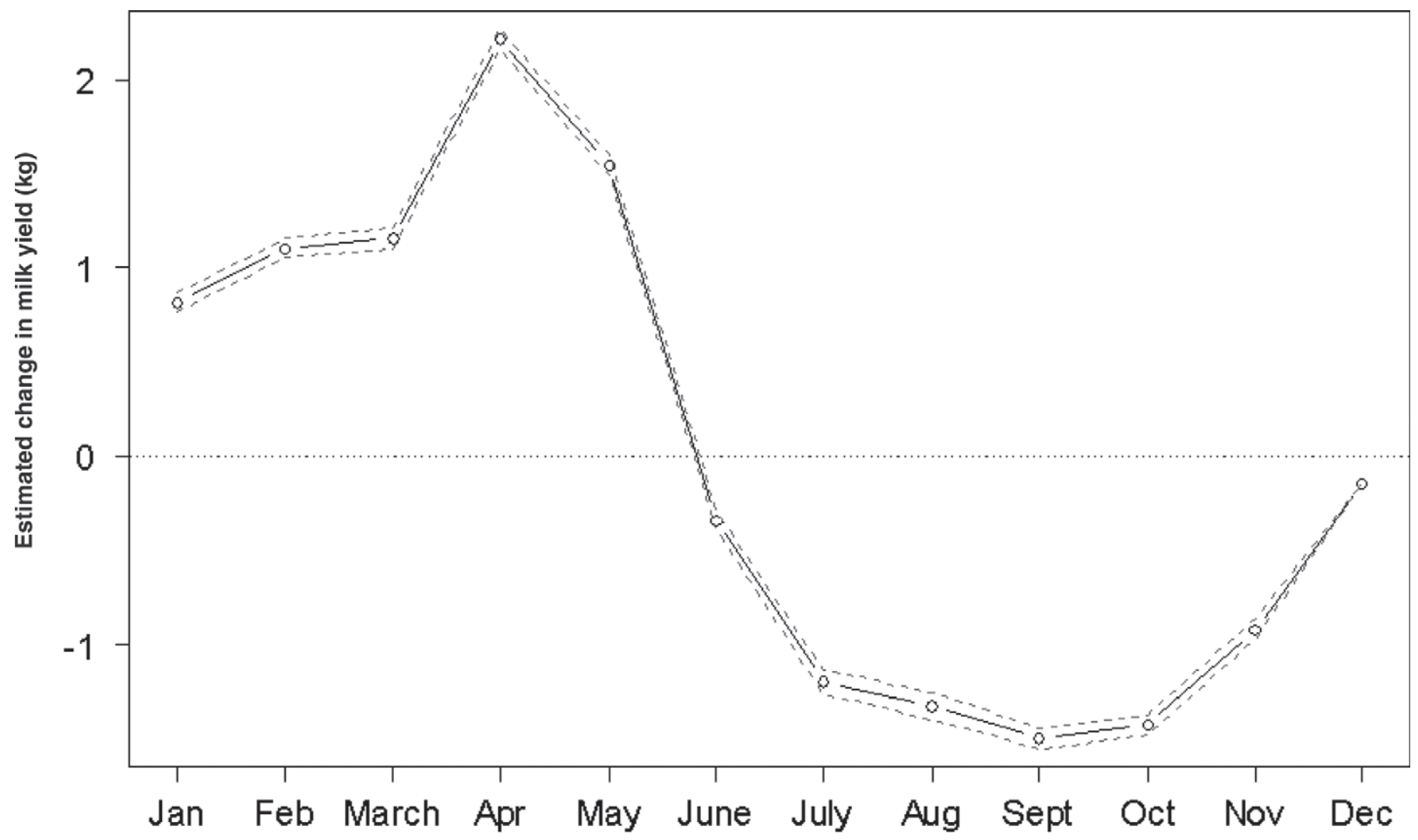

Month of milk yield test day

Figure 3. Estimated changes in milk yield $(\mathrm{kg})$ by month of milk yield test day and $95 \%$ confidence intervals for parity 2 cows in herds located in high-exposure districts (180,608 cows in 3,847 herds).

sponded to TD conducted within the week of the date of clinical suspicion in the herd. For cows in herds exposed at the end of the outbreak period, the period of decline in milk yield was earlier, relative to the date of clinical suspicion. The reduction in milk yield was least severe for herds in low-exposure districts detected early in the outbreak period. The estimated values corresponded to mean effects in a herd under natural conditions of exposure for which the proportion of infected cows per exposed herd was unknown. Therefore, these values likely underestimate the effect of infection for a single infected cow, because even in herds located in high-exposure districts, some cows within a herd would probably not have been infected. Because of the exclusion of case herds located in regions with a very low prevalence, the estimates calculated for herds in the slightly exposed population may overestimate the average effect. Therefore, the corresponding result may not be generalized to case herds in districts with a very low prevalence.

Decreased milk yield was observed $126 \mathrm{~d}$ before the date of clinical suspicion in the herd. This decrease cor- responded with TD predominantly conducted in May 2007. However, because BTV-8 was not detected in May in the geographical areas studied, and the virus has a long transmission cycle, it seems unlikely that there were infected herds in the districts at that time. This deviation from the reference milk yield could be linked to an unknown environmental factor specific to the year 2007 in the northeast of France. Therefore, to avoid overinterpreting the early milk losses, the effect of BTV-8 exposure on milk yield was considered to start from $63 \mathrm{~d}$ before the date of clinical suspicion for herds detected early in the outbreak period. This suggests that viral circulation occurred before the detection of clinical signs in exposed cattle. Indeed, the date of detection of clinical signs does not truly correspond to the date of first infection in an exposed herd. The time interval between initial infection and the date of detection of clinical signs depends on both incubation period and time needed for the detection of clinical signs by the farmer. Moreover, subclinical infections are frequent in cattle and are associated with decrease in milk yield (Santman-Berends et al., 2011). 

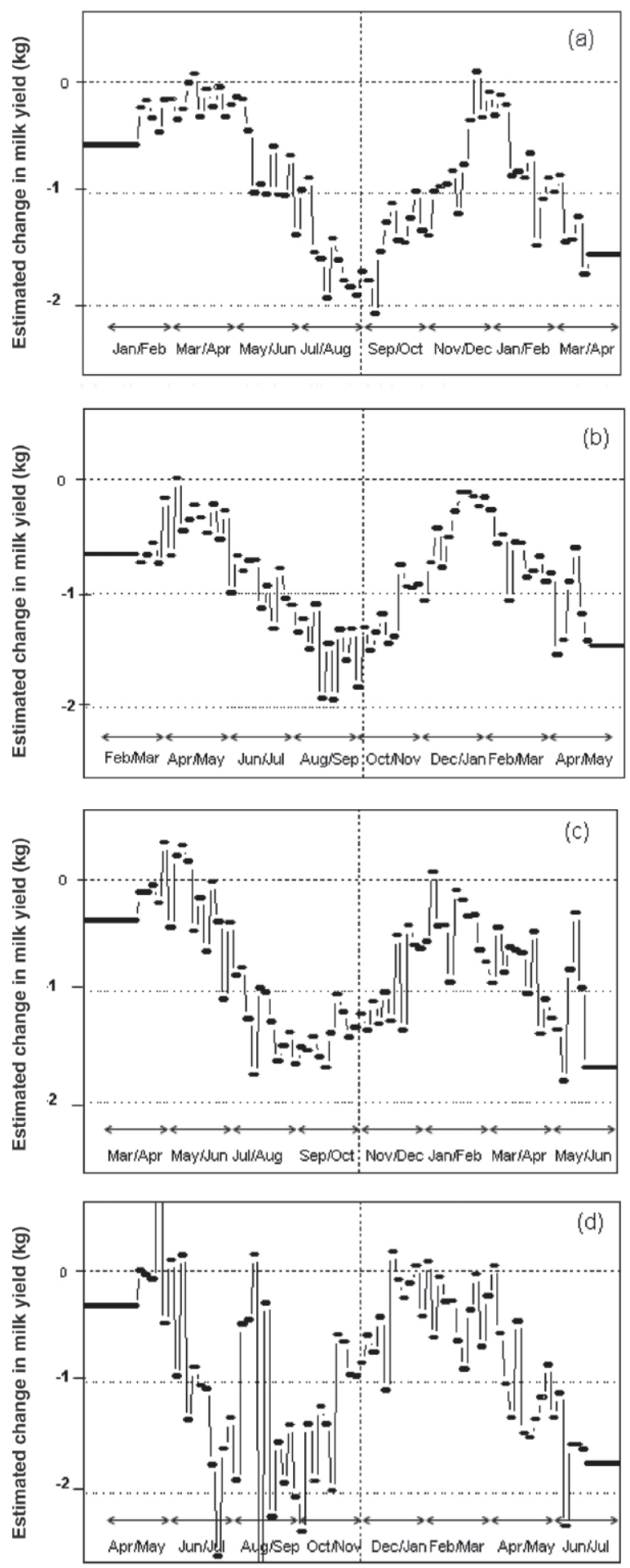

Months during which milk yield test day were conducted

Figure 4. Estimated changes in milk yield $(\mathrm{kg})$ by milk yield test day around the herd date of clinical suspicion by month of clinical suspicion for parity 2 cows in herds located in the moderate-exposure districts [(a) exposed population in September: 7,961 cows in 404 herds; (b) exposed population in October: 10,014 cows in 510 herds; (c) exposed population in November: 5,450 cows in 266 herds; (d) exposed population in December: 2,083 cows in 113 herds; unexposed population: 164,854 cows in 2,974 herds].
Therefore, subclinical or undetected infections occurring in exposed herds could explain the early deviation 2 mo before the disease detection. Decreases in milk yield were identified up to a month before the date of seroconversion of BTV-8-infected cows (which were not clinically diagnosed) in the Netherlands in 2008 (Santman-Berends et al., 2011). Furthermore, exposure to BTV-8 caused variations in fertility 1 mo before the date disease was detected in herds that were identified early in the outbreak period (Nusinovici et al., 2012a).

Milk yield restabilized from $118 \mathrm{~d}$ after the date disease was detected in the herd and this, therefore, was considered the end of the effect of exposure. Such a long duration of effect may be due to the persistence of milk yield loss for individual cows and the time required for viral spread within an exposed herd. For an individual, the impact on milk yield could persist due to the healing time of lesions affecting the teats or udder of cows or those resulting in decreased food intake, such as mouth congestion or foot sores. Such lesions have been reported to regress significantly in a period of 4 to 8 wk (Guyot et al., 2008). The duration of BTV8 effect on milk yield is consistent with the duration of reduced milk yield associated with exposure to the epidemic hemorrhagic disease virus (of the same type as the BTV Orbivirus). Cows exposed at the beginning of the outbreak period showed a significant decrease in milk yield during the 4 mo following the onset of disease (Kedmi et al., 2010). The fact that no decrease in milk yield was observed after the date of seroconversion in cows infected with BTV-8 is probably due to the absence of clinical signs in these cows (Santman-Berends and al, 2011). The decrease in milk yield observed more than $260 \mathrm{~d}$ after the date of detection of the disease could correspond to the reemergence of the virus in 2008. Indeed, TD affected by this reduction were conducted mainly between May 2008 and September 2008, which was during the 2008 outbreak period. Because probably not all the cows were infected in case herds in 2007, some cows were thus still naïve in 2008.

The relatively earlier reduction in milk yield in infected herds detected later in the outbreak period suggests that detection of clinical signs of disease was delayed in these herds. It could be due to a less detectable expression of clinical signs in these herds. This result is consistent with the effects of exposure to BTV8 in 2007 on the fertility of dairy cows (Nusinovici et al., 2012a). Reductions in fertility were observed over 2 mo before clinical signs were reported in herds detected in November and December, whereas for infected herds identified in September, this decline began only $4 \mathrm{wk}$ before clinical signs were reported. Finally, the study that quantified the effect of exposure to the epidemic hemorrhagic disease virus also showed a shorter dura- 

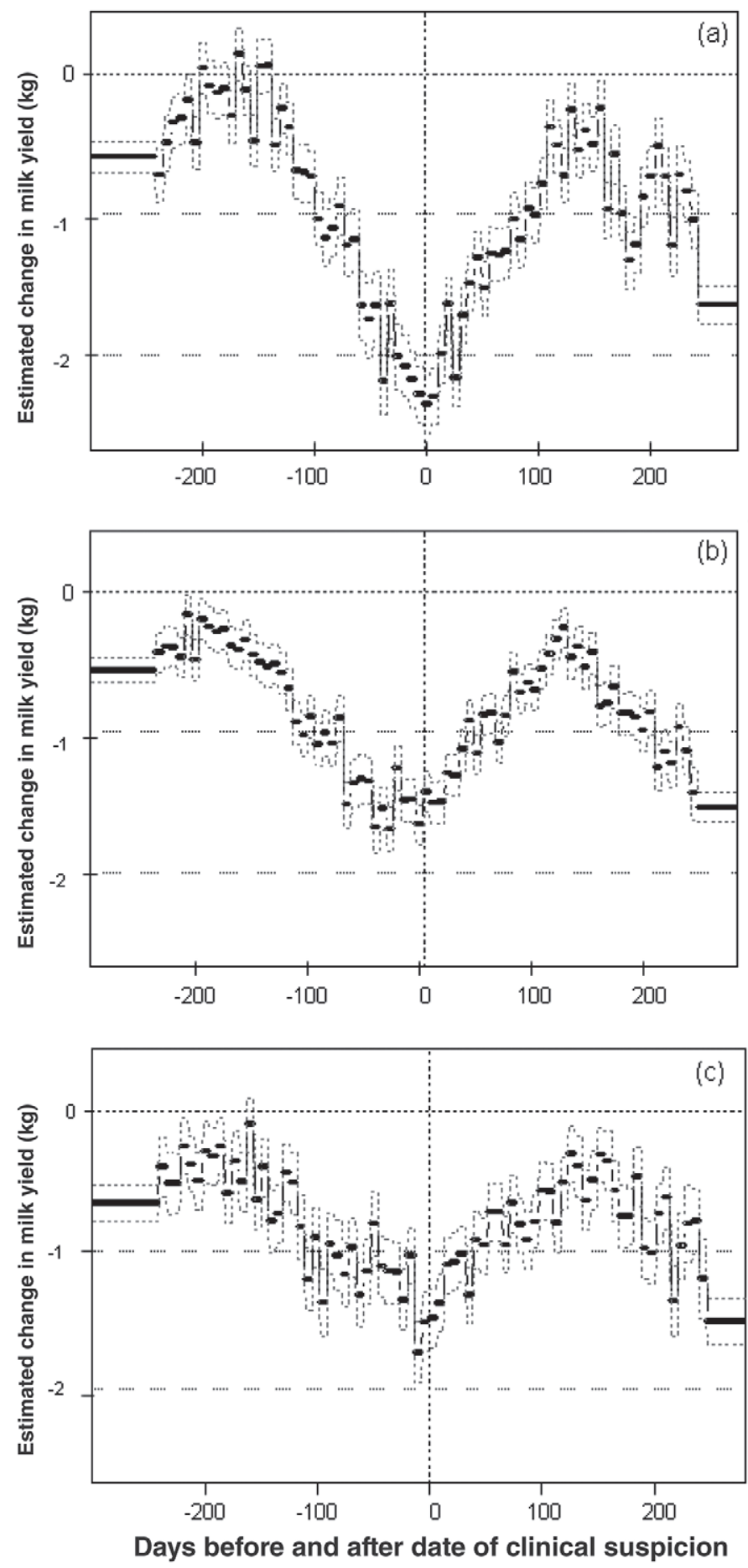

Figure 5. Estimated changes in milk yield $(\mathrm{kg})$ by milk yield test day and $95 \%$ confidence intervals around the herd date of clinical suspicion for parity 2 cows according to the level of exposure: (a) exposed population in high-exposure districts (15,754 cows in 873 herds), (b) exposed population in moderate-exposure districts $(25,915$ cows in 1,315 herds), (c) exposed population in low-exposure districts $(12,373$ cows in 657 herds), and unexposed population (164,854 cows in 2,974 herds). tion of effect for the latest cows exposed. Although the effect before the exposure period was not tested, this could result from a shift in the period of decline in milk yield for those cows exposed later (Kedmi et al., 2010).

The overall effect of exposure on milk yield was lower for cows in infected herds located in districts with the lowest between-herd prevalence. This may be due to a lower within-herd incidence or to a lower amount of virus injected by midges to individual cows in herds located in these districts. This effect of local exposure level was also noted when quantifying the effect of exposure to BTV-8 in 2007 on the risk of abortion (Nusinovici et al., 2012b). When considering the herd-exposure month, estimated losses decreased according to the level of exposure in the district for herds with a suspected infection date in September and October. This could notably be explained by the fact that partial confounding took place between the level of local exposure and the month of clinical suspicion in the herd. Infected farms in the high-exposure districts were generally detected early in the outbreak period, whereas those in low-exposure districts were detected throughout the outbreak period.

The magnitude of the effect of exposure to BTV-8 on milk yield depended on the choice of reference milk yield value. To avoid overestimation of the effect of exposure, 3 scenarios with different values of the reference milk yield were considered. According to these scenarios, the cumulative loss of milk yield was between 1.2 and $3.4 \%$ of annual milk yield. The most conservative scenario (reference milk yield $=$ milk yield of case herd cows recorded $100 \mathrm{~d}$ before BTV-8 exposure) seems unlikely. The cumulative milk yield loss over 6 mo was not significant (results not shown for parity 2 cows located in low-exposure districts) although at least 1 animal showed signs of clinical disease in any case herd. A Dutch study showed an average loss of milk yield associated with BTV-8 infection, which represents less than $1 \%$ of total milk yield during lactation (Santman-Berends et al., 2011). These values were lower than those found in our study, possibly because none of the seroconverted cows showed clinical signs.

The reference population was composed of information from cows of case herds before exposure in 2007. This comparison limited possible confounding factors due to variations of herd management between different regions. However, misinterpretation due to variations of herd management or environment characteristics over time within a given region could remain. Therefore, a second reference population of cows belonging to herds located in areas that were not exposed in 2007 was considered. The similarities in our findings show the robustness of the results. 
Table 2. Cumulative losses in milk yield (MY) from $63 \mathrm{~d}$ before to $118 \mathrm{~d}$ after the date of clinical suspicion with bluetongue virus serotype 8 (BTV-8) for all case herds located in high-exposure districts according to the 3 levels of reference milk yield (exposed population: 46,405 cows in 890 herds; population not exposed: 164,854 cows in 2,974 herds)

\begin{tabular}{|c|c|c|c|c|}
\hline \multirow[b]{2}{*}{ Parity } & \multirow{2}{*}{$\begin{array}{l}\text { Average MY } \\
\text { at } 305 \mathrm{~d}(\mathrm{~kg})\end{array}$} & \multicolumn{3}{|c|}{$\begin{array}{c}\text { Cumulative losses }(\mathrm{kg}) \text { and losses relative to } \\
\text { the average MY at } 305 \mathrm{~d}(\%)\end{array}$} \\
\hline & & Unexposed $^{1}$ & $130 \mathrm{~d}$ after ${ }^{2}$ & 100 d before $^{3}$ \\
\hline Primiparous & 7,240 & $249(3.4)$ & $158(2.2)$ & $67(0.9)$ \\
\hline Parity 2 & 8,291 & $298(3.6)$ & $207(2.5)$ & $116(1.4)$ \\
\hline Parities 3+ & 9,015 & $293(3.2)$ & $202(2.2)$ & $111(1.2)$ \\
\hline
\end{tabular}

${ }^{1}$ Reference milk yield $=$ milk yield of cows from herds not exposed.

${ }^{2}$ Reference milk yield $=$ milk yield of case herd cows $130 \mathrm{~d}$ after the date of clinical suspicion.

${ }^{3}$ Reference milk yield $=$ milk yield of case herd cows $100 \mathrm{~d}$ before the date of clinical suspicion.

\section{CONCLUSIONS}

In a population of naïve cattle herds, the incursion of BTV-8 resulted in a significant decrease in the average milk yield of all cows in infected herds. This decrease was observed before the date of detection of clinical signs in the herd and lasted for several months. Based on the pattern of the estimated losses, it is likely that some herds detected late during the outbreak experienced a delayed detection.

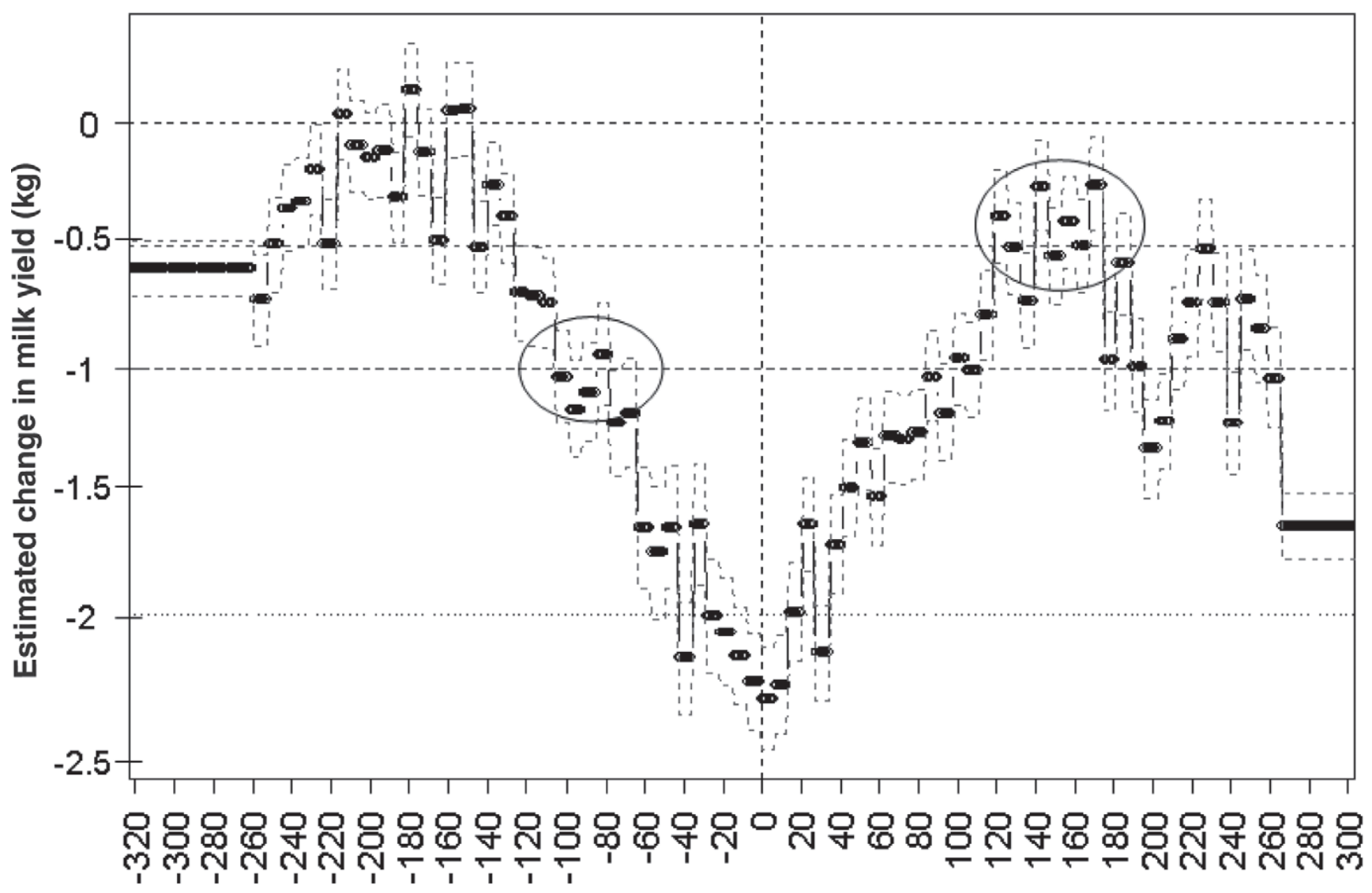

\section{Days before and after date of clinical suspicion}

Figure 6. Estimated changes in milk yield $(\mathrm{kg})$ by milk yield test day and $95 \%$ confidence intervals around the date of herd clinical suspicion for parity 2 cows in herds located in the high-exposure districts (same as in Figure 2). The levels of reference milk yield in the 3 baseline scenarios are shown: milk yield reference $=(\mathrm{a})$ milk yield of the cows from herds not exposed, (b) milk yield of case herd cows $130 \mathrm{~d}$ after the date of clinical suspicion, and (c) milk yield of case herd cows $100 \mathrm{~d}$ before the date of clinical suspicion. Circles correspond to periods of milk yield stabilization used for the definition of the scenarios. 

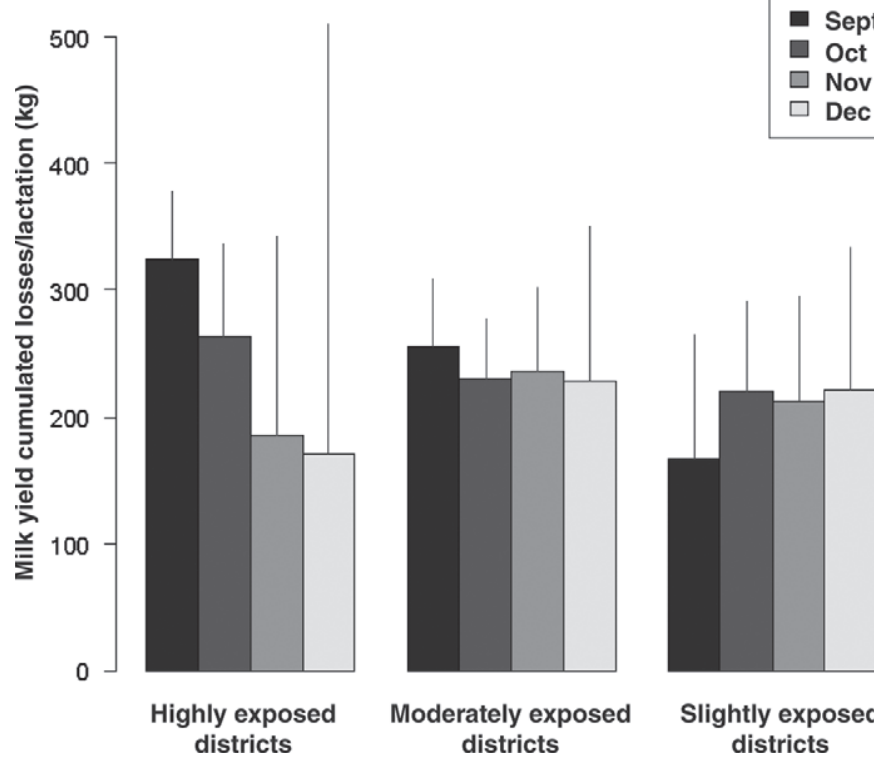

Figure 7. Cumulative lost milk yield associated with exposure to bluetongue virus serotype 8 (BTV-8) levels according to level and month of exposure for parity 2 cows and $95 \%$ confidence intervals (vertical lines); reference milk yield = milk yield of cows in unexposed herds. Cumulative losses were calculated between either $63 \mathrm{~d}$ before and $118 \mathrm{~d}$ after, $93 \mathrm{~d}$ before and $88 \mathrm{~d}$ after, $123 \mathrm{~d}$ before and $58 \mathrm{~d}$ after, or $153 \mathrm{~d}$ before and $28 \mathrm{~d}$ after the date of clinical suspicion for herds exposed in September, October, November, and December, respectively.

\section{ACKNOWLEDGMENTS}

Financial support for this research was provided by INRA (Nantes, France); Cemagref (Antony Cedex, France); and Basse-Normandie, Bretagne, Pays de le Loire, and Poitou-Charentes Regional Councils under the SANCRE project, in the framework of "For and About Regional Development" programs. The authors gratefully acknowledge the Centre de Traitement de l'Information Génétique (INRA, Jouy-en-Josas, France) for providing the performance data and the Ministry of Agriculture (Direction Générale de l'Alimentation, Paris, France) for the BTV case herds data.

\section{REFERENCES}

Bareille, N., F. Beaudeau, S. Billon, A. Robert, and P. Faverdin. 2003. Effects of health disorders on feed intake and milk production in dairy cows. Livest. Prod. Sci. 83:53-62.
Beaudeau, F., M. Belliard, A. Joly, and H. Seegers. 2007. Reduction in milk yield associated with Mycobacterium avium subspecies paratuberculosis (Map) infection in dairy cows. Vet. Res. 38:625-634.

Detilleux, J. C., Y. T. Gröhn, and R. L. Quaas. 1994. Effects of clinical ketosis on test day milk yields in Finnish Ayrshire cattle. J. Dairy Sci. 77:3316-3323.

Durand, B., G. Zanella, F. Biteau-Coroller, C. Locatelli, F. Baurier, C. Simon, E. Le Dréan, J. Delaval, E. Prengère, V. Beauté, and H. Guis. 2010. Anatomy of bluetongue virus serotype 8 epizootic wave, France, 2007-2008. Emerg. Infect. Dis. 16:1861-1868.

Elbers, A. R., A. N. van der Spek, and P. A. van Rijn. 2009. Epidemiologic characteristics of bluetongue virus serotype 8 laboratoryconfirmed outbreaks in the Netherlands in 2007 and a comparison with the situation in 2006. Prev. Vet. Med. 92:1-8.

Elbers, A. R. W., A. Backx, E. Meroc, G. Gerbier, C. Staubach, G. Hendrickx, A. van der Spek, and K. Mintiens. 2008. Field observations during the bluetongue serotype 8 epidemic in 2006: I. Detection of first outbreaks and clinical signs in sheep and cattle in Belgium, France and the Netherlands. Prev. Vet. Med. 87:21-30.

Fourichon, C., H. Seegers, N. Bareille, and F. Beaudeau. 1999. Effects of disease on milk production in the dairy cow: A review. Prev. Vet. Med. 41:1-35.

Gröhn, Y. T., J. J. McDermott, Y. H. Schukken, J. A. Hertl, and S. W. Eicker. 1999. Analysis of correlated continuous repeated observations: Modelling the effect of ketosis on milk yield in dairy cows. Prev. Vet. Med. 39:137-153.

Guyot, H., A. Mauroy, N. Kirschvink, F. Rollin, and C. Saegerman 2008. Clinical aspects of bluetongue in ruminants. Pages $34-52$ in Bluetongue in Northern Europe. C. Saegerman, F. ReviriegoGordejo and P.-P. Pastoret, ed. OIE Publications, Paris, France.

Kedmi, M., M. Van Straten, E. Ezra, N. Galon, and E. Klement. 2010. Assessment of the productivity effects associated with epizootic hemorrhagic disease in dairy herds. J. Dairy Sci. 93:2486-2495.

Lescourret, F., and J. B. Coulon. 1994. Modeling the impact of mastitis on milk production by dairy cows. J. Dairy Sci. 77:2289-2301.

Nusinovici, S., H. Seegers, A. Joly, F. Beaudeau, and C. Fourichon. 2012a. Quantification and at-risk period of decreased fertility associated with exposure to bluetongue virus serotype 8 in naïve dairy herds. J. Dairy Sci. 95:3008-3020.

Nusinovici, S., H. Seegers, A. Joly, F. Beaudeau, and C. Fourichon. $2012 \mathrm{~b}$. Increase in the occurrence of abortions associated with exposure to Bluetongue virus serotype 8 in naïve dairy herds. Theriogenology 78:1140-1151.

Saegerman, C., D. Berkvens, and P. S. Mellor. 2008. Bluetongue epidemiology in the European Union. Emerg. Infect. Dis. 14:539-544.

Saegerman, C., P. Mellor, A. Uyttenhoef, J.-B. Hanon, N. Kirschvink, E. Haubruge, P. Delcroix, J.-Y. Houtain, P. Pourquier, F. Vandenbussche, B. Verheyden, K. De Clercq, and G. Czaplicki. 2010. The most likely time and place of introduction of BTV8 into Belgian ruminants. PLoS ONE 5:e9405.

Santman-Berends, I. M. G. A., J. J. Hage, T. J. G. M. Lam, O. C. Sampimon, and G. van Schaik. 2011. The effect of bluetongue virus serotype 8 on milk production and somatic cell count in Dutch dairy cows in 2008. J. Dairy Sci. 94:1347-1354.

Thiry, E., J. Y. Zimmer, and E. Haubruge. 2008. Bluetongue: Virology, pathogenesis, and biology of the Culicoides vector. Pages 13-25 in Bluetongue in Northern Europe. C. Saegerman, F. ReviriegoGordejo and P.-P. Pastoret, ed. OIE Publications, Paris, France.

Velthuis, A. G., H. W. Saatkamp, M. C. Mourits, A. A. de Koeijer, and A. R. Elbers. 2010. Financial consequences of the Dutch bluetongue serotype 8 epidemics of 2006 and 2007. Prev. Vet. Med. $93: 294-304$. 